\title{
CONTRIBUIÇÃO DO GEAD PARA A PRÁXIS PEDAGÓGICA DE PROFESSORES DA REDE MUNICIPAL DE ANÁPOLIS
}

\author{
Tatiane Custódio da Silva Batista \\ https://orcid.org/0000-0001-9319-3793 \\ Maria Aparecida Rodrigues da Fonseca \\ https://orcid.org/0000-0003-3526-0227
}

\begin{abstract}
Resumo: Este artigo busca analisar os subsídios dos estudos realizados pelo Grupo de extensão e pesquisa em Tecnologias e Educação a Distância (GEaD) para atuação docente no município de Anápolis, além de discutir e evidenciar seus desdobramentos desde a fundação do grupo e a participação da equipe da Rede Municipal de Educação de Anápolis nas pesquisas propostas. Ao apresentarmos o princípio da indissociabilidade no tripé ensino, pesquisa e extensão, pautamos nosso enfoque nesta última atividade e discorremos sobre os impactos nos trabalhos realizados pelo GEaD, com objetivo de refletir acerca do papel dos projetos de extensão enquanto fomentadores da troca de saberes entre a comunidade universitária e a sociedade. Por fim, enfatizamos a importância da extensão universitária por meio do grupo de estudos enquanto instrumento imperativo ao aspecto formativo na rede municipal supracitada.
\end{abstract}

Palavras-chave: Extensão Universitária. GEaD. Desdobramentos. Atuação docente. SME/ Anápolis.

\section{GEAD CONTRIBUTION TO THE PEDAGOGICAL PRACTICE OF TEACHERS OF THE MUNICIPAL NETWORK OF ANÁPOLIS}

\begin{abstract}
This article seeks to analyze the subsidies of the studies carried out by the extension and research Group on Technologies and Distance Education (GEaD) for teaching in the city of Anápolis, besides discussing and evidencing its developments since the founding of the group and the participation of the team of the Municipal Education Network of Annapolis in the proposed research. In presenting the principle of indissociability in the tripod teaching, research and extension, we focus our focus on this last activity and discuss the impacts of extension in the works carried out by GEaD, in order to reflect on the role of extension projects as promoters of knowledge exchange between the university community and society. Finally, we emphasize the importance of university extension through the study group as an imperative instrument for the training aspect in the mentioned municipal network.
\end{abstract}

Keywords: University Extension. GeaD. Splits. Teaching performance. SME/Anápolis. 


\section{CONTRIBUCIÓN DEL GEAD PARA LA PRÁXIS PEDAGÓGICA DE PROFESORES DE LA RED MUNICIPAL DE ANÁPOLIS}

Resumen: Este artículo busca analizar los subsidios de los estudios realizados por el Grupo de extensión e investigación en Tecnologías y Educación a Distancia (GEaD) para actuación docente en el municipio de Anápolis, además de discutir y evidenciar sus desdoblamientos desde la fundación del grupo y la participación de la agrupación el equipo de la Red Municipal de Educación de Anápolis en las encuestas propuestas. Al presentar el principio de la indisociación en el trípode enseñanza, investigación y extensión, pautamos nuestro enfoque en esta última actividad y discordamos sobre los impactos de la extensión en los trabajos realizados por el GEaD, con el objetivo de reflexionar acerca del papel de los proyectos de extensión como fomentadores del intercambio de saberes entre la comunidad universitaria y la sociedad. Por último, enfatizamos la importancia de la extensión universitaria por medio del grupo de estudios como instrumento imperativo al aspecto formativo en la red municipal arriba citada.

Palabras clave: Extensión Universitaria. Esmerilado. Desarrollos. Actuación docente. SME/ Anápolis.

Submetido em: 01/12/2018

Aceito em: 21/12/2018

\section{INTRODUÇÃO}

Ao compreendermos a extensão universitária como ato educativo, cultural e científico articulado ao ensino e à pesquisa de forma indissociável e como processo viabilizador da relação de transformação entre a universidade e a sociedade, buscamos compreendê-la enquanto uma via de mão-dupla, com circulação assegurada à comunidade acadêmica, que encontra oportunidade para construção da práxis de um determinado conhecimento acadêmico. Neste exercício, são possibilitados aprendizados que, a partir de uma reflexão teórica, são acrescidos a esse conhecimento (NUNES; SILVA, 2011).

Nesse contexto, enfatizamos a indissociabilidade entre ensino, pesquisa e extensão presentes nas universidades públicas, que, além de contribuir com o processo educacional de indivíduos em sua essência, também, no caso da extensão universitária, aproxima a sociedade da universidade, minimizando o gargalo entre estes dois atores.

Neste artigo, não deixamos de tecer as inter-relações entre a tríade ensino, pesquisa e extensão, todavia, propomos empreender análises e discussões sobre a extensão universitária por meio de sua relação e seu direcionamento para as ações e os estudos realizados no Grupo de Extensão e Pesquisa 
em Tecnologias e Educação a Distância $(\mathrm{GEaD})$ da Universidade Federal de Goiás pesquisado, sem a intencionalidade de esgotar o tema.

Deste modo, objetivamos analisar os subsídios dos estudos realizados no GEaD para atuação docente no município de Anápolis, além de discutir e evidenciar seus desdobramentos desde a sua fundação e a participação da equipe da Rede Municipal de Educação de Anápolis nas pesquisas propostas. Assim, discorremos sobre os impactos da extensão nos estudos realizados pelo GEaD, no município em questão, refletindo acerca do papel dos projetos de extensão enquanto fomentadores da troca de saberes entre a comunidade universitária e a sociedade, e concluímos que esta atividade, realizada por meio do grupo de estudos, tem sido um instrumento imperativo no aspecto formativo, na Rede Municipal de Anápolis, por apresentar desdobramentos contributivos ao trabalho docente e à formação continuada dos envolvidos, aspectos expressos e refletidos no decorrer deste texto.

\section{A EDUCAÇÃO SUPERIOR E A EXTENSÃO UNIVERSITÁRIA}

Ao empreendermos um estudo sobre a gênese da universidade, é possível verificar sua consolidação enquanto instituição entre os séculos XII e XIII. Sobre o ensino superior e a Universidade no Brasil, Cunha (2000) aponta que o primeiro estabelecimento foi fundado pelos Jesuítas na Bahia, em 1550, e que no século XIX implementaram-se outras estruturas que seguiam o modelo napoleônico e se reconfiguraram ao longo dos tempos. Nunes e Silva (2011), corroborando a discussão, assinala que essas instituições foram criadas para servir às necessidades do país, funcionando como um espaço para o desenvolvimento e a conglobação do conhecimento e da formação de cidadãos.

No que diz respeito a esta temática, Oliveira (2010) relata que as primeiras universidades foram institucionalizadas a partir do Estatuto das Universidades Brasileiras, promulgado pelo Decreto de $\mathrm{n}^{\circ}$ 19.851, em 11 de abril de 1931. O autor evidencia que, nos anos de 1960, houve um movimento de expansão desse nível de ensino, mas somente no regime militar em 1968 aconteceu a Reforma Universitária, dando ênfase à indissociabilidade entre ensino, pesquisa e extensão. Conforme atesta, essa reforma contribuiu também para a constituição dos direitos docentes de tempo integral e a questão da dedicação exclusiva. "Assim, a pós-graduação e a pesquisa, articulados à carreira docente, produziram uma mudança qualitativa do magistério, não só nas 
universidades federais, como também, nas estaduais e privadas" (CUNHA, 2010, p. 188).

Nunes e Silva (2011, p. 128) apontam que "a universidade desde sua origem já passou por várias transformações”. Atualmente, o Decreto n 9.235, de 15 de dezembro de 2017, que dispõe sobre o exercício das funções de regulação, supervisão e avaliação das instituições de educação superior, assinala que essas instituições, de acordo com sua organização e suas respectivas prerrogativas acadêmicas, são credenciadas como faculdades, centros universitários e universidades. A estrutura atual da educação superior no Brasil pode ser compreendida conforme representado na Figura 1 a seguir.

FIGURA 1 - ORGANIZAÇÃO DA EDUCAÇÃO SUPERIOR NO BRASIL

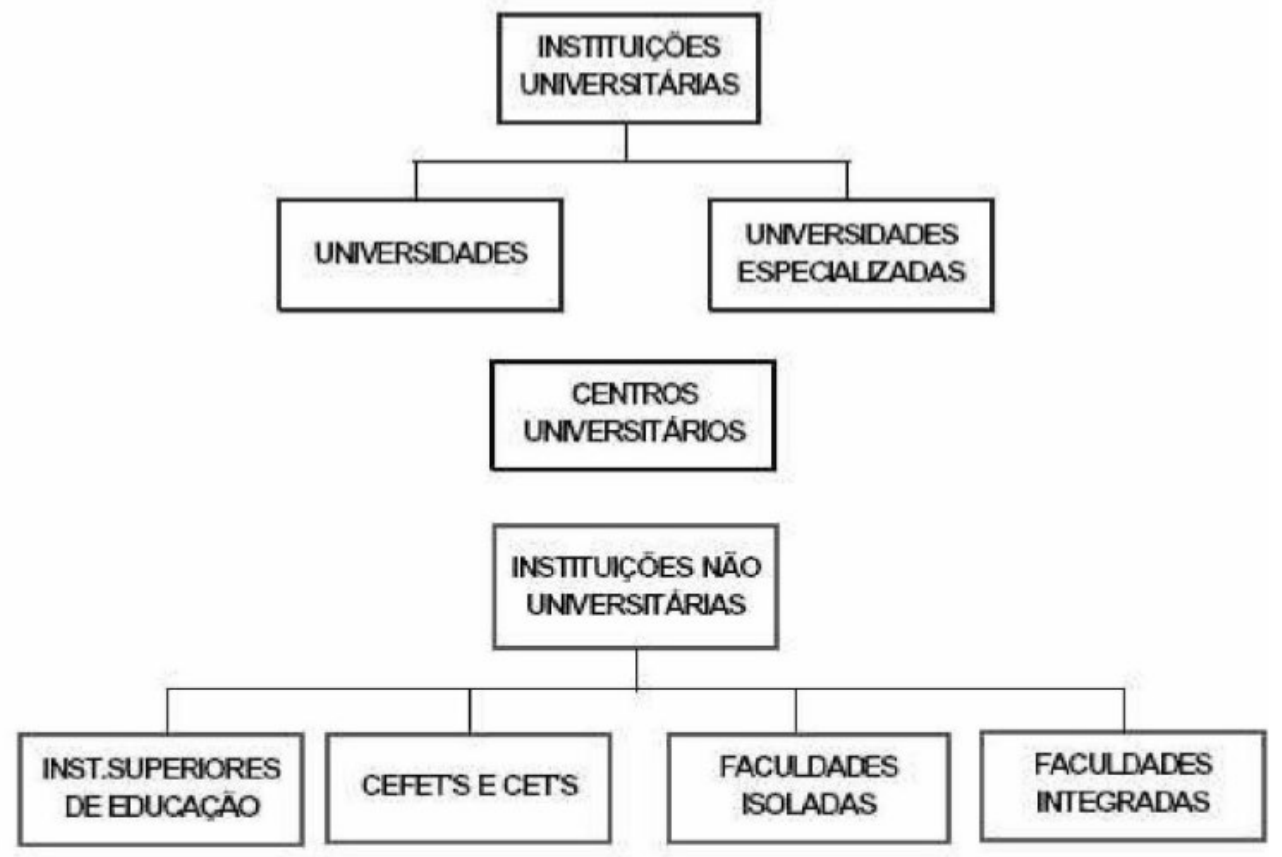

FonTE: ElABoradA PELAS AUtORAS COM BASE EM CUNHA (2000).

Nunes e Silva (2011, p. 120) afirmam que as universidades foram criadas no Brasil para atender às necessidades locais, e distribuídas por todo o território nacional, estando associadas ao desenvolvimento econômico, social, cultural e político. Privilegiadamente, elas se constituem como lócus para produção e acumulação de conhecimento e formação de cidadãos.

Segundo a Constituição Federal de 1988, em seu art. 207, "As universidades gozam de autonomia didático-científica, administrativa e de gestão financeira 
e patrimonial, e obedecerão ao princípio de indissociabilidade entre ensino, pesquisa e extensão" (BRASIL, 1988). Por meio da extensão, a universidade tem a oportunidade de levar à comunidade conhecimentos produzidos pelas pesquisas e normalmente divulgados com o ensino.

Dessa forma, ao buscarmos compreender a extensão universitária, vemos uma forma de interação que deve existir entre a instituição e a comunidade na qual está inserida, configurando-se como uma espécie de ponte permanente entre a Instituição de Ensino Superior (IES) e os diversos setores da sociedade.

O fortalecimento da relação universidade/sociedade prioriza a superação das condições de desigualdades e exclusão existentes. Através de projetos sociais, a universidade socializa seu conhecimento e disponibiliza seus serviços, exercendo sua responsabilidade social, ou mesmo sua missão: o compromisso com a melhoria da qualidade de vida dos cidadãos. (NUNES; SILVA, 2011, p. 121).

Para as autoras, esta faceta é uma das principais pontes para a reflexão quanto ao papel do ensino superior neste novo milênio, pois, quando as necessidades forem naturalmente percebidas pela comunidade acadêmica e incluídas no seu fazer, as IES estarão cumprindo com sua finalidade.

\footnotetext{
Portanto, se a extensão universitária é um processo educativo, cultural e científico que viabiliza a relação entre universidade e sociedade, a universidade pública enquanto um espaço de criação e recriação de conhecimento deve ser acima de tudo pública e, para tanto, a transformação social deve extrapolar os muros acadêmicos. Aqui, a universidade deve ser mais do que um laboratório, objeto de estudo ou campo de pesquisas, mas também uma instituição com pessoas, demandas, reivindicações, anseios e saberes que se encontram dentro e fora da universidade. (NUNES; SILVA, 2011, p. 122).
}

As autoras evidenciam, portanto, o papel educativo da extensão universitária, assim como ressaltam a cultura e a ciência como elementos mediadores da construção de conhecimento, comprovando a relação existente entre a instituição e a comunidade local. Entretanto, a ênfase recai sobre a instituição pública enquanto lugar de transformação social ao transpor o espaço universitário, vindo ao encontro de anseios e reivindicações das pessoas.

Paula (2013, p. 9) afirma que, na extensão, as universidades atuam verdadeiramente no âmbito social, ao mesmo tempo, é nesse contexto que “[...] o Estado e outras instituições responsáveis pela manutenção da ordem social despertaram para a necessidade de oferecer políticas capazes de atender/ 
neutralizar reivindicações operário-populares”. Nunes e Silva (2011, p. 124) ainda apontam que, “[...] por meio da extensão, a universidade tem a oportunidade de levar à comunidade os conhecimentos de que é detentora, os novos conhecimentos produzidos pela pesquisa e normalmente divulgados com o ensino". Assim, ao realizar a extensão, a universidade efetivamente socializa e democratiza o conhecimento. Desta forma, “[...] o conhecimento não se traduz em privilégio apenas da minoria que é aprovada no vestibular, mas difundido pela comunidade, consoante os próprios interesses dessa mesma comunidade" (NUNES; SILVA, 2011, p. 124).

Diante do que fora apresentado e corroborando a visão de que a extensão é um mecanismo de socialização e democratização do conhecimento, bem como um termômetro entre universidade e sociedade, discorremos a seguir sobre o Grupo de Estudo de Educação a Distância como experiência de extensão universitária.

2.1 Grupo de Estudos e Pesquisas em Educação a Distância e a extensão universitária

O GEaD foi instituído em agosto de 2014, sob coordenação da professora Daniela da Costa Britto Pereira Lima (professora efetiva da UFG). A iniciativa se dá a partir de uma proposta que objetiva:

[...] realizar estudos analíticos sobre a Educação a Distância, com vistas a refletir e debater seu conceito, formas de organização pedagógica, estrutura, gestão e políticas públicas. Buscamos analisar as ações de formação de professores que fazem uso da modalidade, estudando as políticas públicas balizadoras desse processo, seus marcos regulatórios e indicadores de expansão. (GEaD, 2014).

De acordo com o site do grupo, suas principais ações voltam-se para os estudos e as pesquisas sobre Ensino a Distância (EaD), Tecnologias Digitais de Informação e Comunicação (TDIC) na educação e políticas públicas para formação de professores; grupos de trabalho para construção de documento técnico sobre as políticas públicas, programas, planos e ações da EaD e uso das tecnologias na educação; análise dos dados de expansão da EaD no Brasil, planejamento e realização de evento sobre as temáticas pesquisadas e estudadas.

Composto por 29 pessoas, em sua grande maioria participantes desde os primeiros encontros realizados em 2014, o grupo tem organização multi-institucional e possui integrantes da Universidade Federal de Goiás; da Secretaria 
Municipal de Educação (SME) de Anápolis; do Núcleo de Tecnologia Educacional da Secretaria Estadual de Educação de Goiás; do Instituto Federal Goiano (IF Goiano); da Secretaria Municipal de Educação de Goiânia; da Secretaria Municipal de Educação de Goianésia; e da Universidade Estadual de Goiás (UEG).

Como desdobramentos e resultados dos estudos realizados a partir de indicações e trabalhos, indicamos principalmente as pesquisas de âmbitos local e regional financiadas por agências de fomento, eventos locais e regionais organizados pelos integrantes do grupo, com participação e publicação em eventos nacionais e internacionais. As atividades desenvolvidas tiveram impactos significativos na Rede Municipal de Educação de Anápolis, aspectos sobre os quais tratamos a seguir.

2.2 A Rede Municipal de Educação de Anápolis e o despertar para o estudo sobre Educação a Distância

A história do GEaD no município de Anápolis principiou pelo Centro de Formação dos Profissionais em Educação de Anápolis (CEFOPE) e pelo Grupo de Estudos das Novas Tecnologias Educacionais (GENTE/Anápolis) que faz parte da Rede Goiana de Pesquisas da Fundação de Amparo à Pesquisa de Goiás (FAPEG) - REDUCATIVA.

O CEFOPE é um setor da Secretaria Municipal de Educação da Prefeitura de Anápolis que tem a responsabilidade de propor, viabilizar e executar a política de formação continuada dos professores e dos profissionais não docentes das unidades de ensino vinculadas à pasta. Tem sua origem vinculada ao Teleposto criado pela Rede Estadual no final da década de 1990. Em 1997 foi inaugurado o Teleposto da Superintendência Municipal de Educação de Anápolis. Como primeira ação, conseguiu-se junto à Procuradoria-Geral do Município que os certificados de participação nos cursos fossem expedidos pelo próprio Teleposto, de forma a assegurar ao professor o direito de usá-la para solicitar Titularidade. O então Teleposto, hoje Centro de Formação dos Profissionais em Educação (CEFOPE), oferece mais que cursos, promove seminários, colóquios, congressos, oficinas de aperfeiçoamento, enriquecimento e grupos de estudos. Além de cursos direcionados a reflexão dos componentes curriculares do ensino fundamental e sobre gestão escolar. O CEFOPE também realiza algumas atividades, tais como: elaboração e execução de experiências formativas junto aos professores alfabetizadores da Rede Municipal de Educação que se baseia nos princípios metodológicos da pesquisa ação. Apoia instituições de ensino superior e de pesquisa no planejamento e organização de eventos na área da educação, tais como: o Centro de Estudos e Pesquisa em Didática (CEPED http://www.ceped.ueg.br) e o programa de mestrado multidisciplinar do Centro Universitário de Anápolis; contribui 
com a capacitação de servidores das outras secretarias da Prefeitura Municipal de Anápolis e acompanha as atividades formativas promovidas pelo MEC, na Rede Anapolina de ensino. (CEFOPE, 2018).

Em relação ao grupo GENTE, no ano de 2014 ele era composto por 9 pessoas, as quais tinham assumido o desafio de contribuir com o Conselho $\mathrm{Mu}$ nicipal de Educação, no sentido de elaborar uma resolução que estabelecesse diretrizes para a oferta de cursos a distância pelo Centro de Formação dos Profissionais em Educação de Anápolis.

Diante da expressiva atuação do CEFOPE na cidade de Anápolis, bem como do espaço e da ascensão que a educação a distância vem empreendendo, entendeu-se que era necessário implementar cursos por meio desta mobilidade educacional, já que as possibilidades eram bem positivas. Contudo, o Conselho Municipal de Educação, órgão mediador e articulador da relação entre a sociedade e os gestores da educação municipal, que, dentre suas múltiplas funções, é responsável por normatizar e elaborar as regras que adaptam para o município as determinações das leis federais e/ou estaduais, assim como legalizar cursos e deliberar sobre o currículo da rede municipal de ensino, não possuía membros com conhecimento específico na área de Educação a Distância.

Diante desse contexto, o Conselho Municipal de Educação, ciente de estudos e produções científicas já realizados pelo GENTE/Anápolis, solicitou ao CEFOPE uma parceria na elaboração das diretrizes para os cursos a distância oferecidos por este Centro de Formação. Este, por sua vez, ao buscar estabelecer parcerias com faculdades e universidades, no sentido de ampliar as oportunidades de estudos sobre a temática em questão, foi informado sobre o Grupo de Estudos de Educação a Distância, que começaria suas atividades no segundo semestre de 2014. Então, em agosto desse ano, no primeiro encontro do GEaD, cinco componentes do GENTE/Anápolis participaram da aula "inaugural" e passaram a integrar o grupo.

Nunes e Silva (2011, p. 124) indicam que "[...] a universidade vai até a comunidade ou, por vezes, pode receber pessoas da comunidade em seu campus, prestando-lhes serviços, assistência, auscultando-lhes os anseios". A comunidade anapolina, por meio do GENTE/Anápolis, foi até a universidade amparada pelo GEaD e encontrou subsídios direcionadores dos estudos necessários para o fim buscado pela rede educacional. 
Ao longo dos encontros, além de textos e legislações lidos e estudados, houve momentos de reflexões sobre a elaboração da resolução com sugestões de diretrizes para os cursos de EaD para o CEFOPE. Após longos momentos de estudos e embates, não apenas nos encontros em Goiânia, mas também do GENTE/Anápolis, no segundo semestre de 2015, consolidou-se o documento que seria a resolução com sugestões de diretrizes para os cursos de $\mathrm{EaD}$ oferecidos pelo CEFOPE.

Devido a algumas situações, dentre elas a troca de gestores municipais das secretarias e departamentos da Rede Municipal de Educação de Anápolis, a ideia da implementação da EaD no CEFOPE não obteve êxito, ficando renegada ao esquecimento. Ainda, por falta do incentivo financeiro concedido pela Secretaria Municipal de Educação, as atividades do GENTE/Anápolis foram paralisadas e assim permanecem até os dias atuais. Todavia, os estudos e a participação nos encontros do GEaD continuaram para a maioria dos integrantes e apresentaram alguns desdobramentos na vida dessas pessoas, bem como em suas atuações enquanto profissionais da educação na cidade de Anápolis. Fatores que merecem ser refletidos.

2.3 O GEaD enquanto atividade de extensão e os desdobramentos na Rede Municipal de Educação de Anápolis

Nunes e Silva (2011, p. 126) evidenciam que “[...] a relação entre pesquisa e extensão ocorre quando a produção do conhecimento é capaz de contribuir para a transformação da sociedade”. A partir deste apontamento, observamos que a atividade de extensão universitária deve causar impacto na sociedade. Sendo assim, quando analisamos a atuação do $\mathrm{GEaD}$, percebemos o quanto esta tem sido impactante para seus membros, especialmente os da SME/Anápolis, devido a sua proposta.

Diante desta constatação, quatro são os aspectos que merecem destaque, sendo o primeiro relacionado a seus componentes, graduados, graduandos, especialistas, mestres, mestrandos, doutores e doutorandos, além de bolsistas de iniciação científica e diversos visitantes que participam aleatoriamente dos estudos, por interesse pelas atividades desenvolvidas, sendo que alguns ainda não têm relação com a educação superior. Mesmo com toda diversidade formativa constituinte dos membros desse grupo, durante as discussões, todos falam e expõem suas ideias. O clima entre os componentes é de muita harmonia, respeito e companheirismo, além do grau de comprometimento de todos 
com o trabalho desenvolvido, fator importante para elevação da autoestima e da capacidade de falar em público, expor e compreender temas estudados.

Os participantes do GEaD ligados à SME/Anápolis atestam o modo como os desdobramentos dos estudos realizados e das experiências vivenciadas contribuíram para atuação de integrantes ou ex-integrantes em cursos de graduação, especialização e ou de formação continuada, ministrando disciplinas, módulos e ou oficinas sobre EaD e TDICs na área de educação.

O segundo ponto a ser destacado é em relação às produções acadêmicas. O GEaD, ainda nos primeiros anos de existência, desenvolveu um Documento Técnico sobre Regulamentação, Programas e Ações da Educação Superior a Distância e do uso das Tecnologias de Informação e Comunicação (TICs) nos governos Fernando Henrique Cardoso, Luiz Inácio Lula da Silva e Dilma Vana Rousseff, no qual as integrantes da SEM/Anápolis tiveram importante participação. Também merecem destaque as produções acadêmicas que culminaram em participação e apresentação em eventos científicos, bem como as diversas publicações, como a produção e a apresentação de artigos científicos na reunião regional da Associação Nacional de Pós-Graduação e Pesquisa em Educação (Anped) no Centro-Oeste, em 2016, no primeiro e segundo Seminário da EaD na Região Centro-Oeste, na reunião regional da Anped Centro-Oeste em 2018, dentre outros, com temáticas vinculadas à rede educacional de Anápolis.

Como terceiro ponto, damos ênfase à interação do grupo com os autores lidos e estudados. Entre ler uma obra, refletir sobre ela e ter a oportunidade de poder ouvir o autor discorrer sobre o que produziu ou vivenciou existe uma diferença, e importa a possibilidade de poder contribuir com aqueles que se dispuseram a tal ação. Sabendo desse diferencial, a coordenadora do grupo propôs que, nos últimos encontros de 2018 e nos encontros de 2019, os autores dos textos selecionados para estudo discutissem suas obras nos encontros do GEaD com os membros participantes. Essa proposta foi e será possibilitada pelas Tecnologias Digitais de Informação e Comunicação, o que faz toda a diferença, não apenas pelos motivos citados anteriormente, mas também por se tratar de um grupo de estudos de Educação a Distância.

Assim, por webconferência, o $\mathrm{GEaD}$ proporciona que seus integrantes estudem textos de diversas regiões do país. Ao discutir, interagir e analisar esses materiais com os autores em tempo real, situação que tem se caracterizado como uma possibilidade ímpar para estes pesquisadores apreenderem as temáticas discutidas, isto se constitui como propriedade para disseminar o 
conhecimento. Toda essa conjuntura tem se materializado na SEM/Anápolis, cujas integrantes anapolinas têm levado o conhecimento construído a partir dessas discussões às escolas da rede, a departamentos da SEM e a algumas instituições superior nas quais atuam.

Por fim, o quarto aspecto a ser destacado como contribuição do GEaD enquanto extensão universitária é o fator formação continuada, sendo este ponto de muitos desdobramentos para as profissionais da SEM/Anápolis que compõem o grupo de estudo. Quando da materialização do grupo em 2014, 5 das 10 integrantes tinham terminado a graduação e não deram continuidade aos estudos, 2 cursavam o mestrado, 2 já tinham terminado o mestrado e 1 estava com uma especialização em andamento. Hoje o grupo possui 1 candidata ao mestrado, 1 mestranda, 4 mestres 4 aspirantes ao doutorado.

A esse respeito, Nunes e Silva (2011) destacam que a intersecção sociedade e universidade, no que se refere à extensão, ultrapassa a clássica disseminação de conhecimento, pois apoia-se na real participação da comunidade na própria atuação da universidade. Vemos a fala das autoras materializada no GEaD enquanto atividade de extensão universitária e o desdobramento na práxis de suas integrantes vinculadas à SME/Anápolis. Elas ainda destacam a importância do ensino, pesquisa e extensão no fazer acadêmico e assinalam que "[...] a relação entre o ensino e a extensão conduz a mudanças no processo pedagógico, pois alunos e professores constituem-se em sujeitos do ato de aprender" (NUNES; SILVA, 2011, p. 126). Nesse sentido, Paula (2013, p. 22) assegura que, na extensão universitária, há “[...] um compromisso, indispensáveis à plena realização da universidade como instrumento emancipatório".

Corroboramos essa assertiva com base nas ações analisadas e desenvolvidas pelo GEaD e seu desdobramento, principalmente no município de Anápolis, e percebemos a construção de conhecimentos em um espaço privilegiado de relações. Destaca-se, ainda, a íntima relação da extensão, ensino e pesquisa por meio da qual o grupo consegue garantir seu caminhar e de todos os integrantes em consonância com esse tripé da universidade.

\section{CONSIDERAÇÕES FINAIS}

Tendo em vista as percepções quanto aos subsídios dos estudos realizados no Grupo de Educação a Distância da UFG para a atuação docente no município de Anápolis, percebemos, no trajeto evidenciado, que as contribuições 
se apresentam em diversos campos e auxiliam no traçado de horizontes e caminhos para conquista do objetivo inicial do grupo GENTE - a resolução que estabelece diretrizes para oferta de cursos a distância pelo Centro de Formação dos Profissionais em Educação de Anápolis. Proposta que possibilita desdobramentos para a equipe da Rede Municipal de Educação de Anápolis em tais estudos enquanto objetos de pesquisa.

Desta forma, destacamos algumas contribuições para a formação e atuação destes professores no município supracitado, como a articulação, o envolvimento e a colaboração a partir da diversidade formativa constituinte dos membros do grupo; as orientações, incentivos e capacitação em relação a produções acadêmicas e participação em estudos e eventos; a interação do grupo com os autores lidos e estudados, possibilitando diálogos, questionamentos e maior entendimento de estudos e temáticas; e o fator formação continuada através do conhecimento teórico e prático dos diversos temas que envolvem os fazeres docente e acadêmico de modo inter-relacionado.

Portanto, entendemos a extensão universitária como um processo educativo, cultural e científico que viabiliza a relação entre universidade e sociedade. Ao pensar a instituição como espaço de criar e recriar conhecimentos, esta deve ser verdadeiramente pública, de modo que a transformação social deve exceder os muros acadêmicos. Nesse sentido, a universidade constituiu-se mais do que um laboratório, objeto de estudo ou campo de pesquisas, mas se alicerça enquanto "[...] instituição com pessoas, demandas, reivindicações, anseios e saberes que se encontram dentro e fora da universidade" (NUNES; SILVA, 2011, p. 122).

Destarte, ansiamos que as atividades de extensão se aprofundem tanto que desapareçam enquanto tais e passem a ser parte integrante das práticas de investigação e de ensino, percepções que temos em relação ao GEaD.

\section{REFERÊNCIAS}

BRASIL. Decreto no 19.851, de 11 de abril de 1931. Dispõe que o ensino superior no Brasil obedecerá, de preferência, ao sistema universitário, podendo ainda ser ministrado em institutos isolados, e que a organização técnica e administrativa das universidades é instituída no presente decreto, regendo-se os institutos isolados pelos respectivos regulamentos, observados os dispositivos do seguinte Estatuto das Universidades Brasileiras. Disponível em: www.fis.ufba.br/dfes/PDI/financ/decreto\%2019.851.doc/. Acesso em: 22 nov. 2018. 
Constituição Federal (1988). Constituição da República Federativa do Brasil de 1988.

Decreto no 9.235, de 15 de dezembro de 2017. Dispõe sobre o exercício das funções de regulação, supervisão e avaliação das instituições de educação superior e dos cursos superiores de graduação e de pós-graduação no sistema federal de ensino. Diário Oficial da União, [Brasília, DF], 18/12/2017. Disponível em: https://www2.camara.leg. br/legin/fed/decret/2017/decreto-9235-15-dezembro-2017-785940-publicacaooriginal-154513-pe.html/ Acesso em: 22 nov. 2018.

CEFOPE. Centro de Formação de Profissionais em Educação. Disponível em: http://anapolis.go.gov.br/portal/secretarias/educacao/pagina/centro-de-formacao-de-profissionais-da-educacao/http://anapolis.go.gov.br/portal/secretarias/educacao/pagina/ centro-de-formacao-de-profissionais-da-educacao/. Acesso em: 10 dez. 2018.

CUNHA, Luiz Antônio. O ensino superior e a universidade no Brasil. In: CUNHA, Luiz Antônio. 500 anos de educação no Brasil. Belo Horizonte: Autêntica, 2000. p. 151-204.

GEaD. Grupo de Estudo em Educação a Distância, 2014. Disponível em: https://nedesc. fe.ufg.br/p/19194-grupo-de-estudos-e-pesquisas-em-educacao-a-distancia-gead. Acesso em: 10 dez. 2018.

NUNES, Ana Lucia de Paula Ferreira; SILVA, Maria Batista da Cruz. A extensão universitária no ensino superior e a sociedade. Mal-Estar e Sociedade, v. 4, n. 7, p. 119-133, 2011. OLIVEIRA, João Ferreira. Educação superior. 2010. Disponível em: http://www.gestrado.net.br/?pg=dicionario-verbetes\&id=255/. Acesso em: 10 dez. 2018.

PAULA, João Antônio de. A extensão universitária: história, conceito e propostas. Interfaces Revista de Extensão, v. 1, n. 1, p. 05-23, jul./nov. 2013. 